\title{
Prevalence of Mental Retardation in Children of Shimoga District-An Overview
}

\author{
K. S. Ramprasad ${ }^{*}$, R. Manjunathaswamy ${ }^{2}$ \\ ${ }^{1}$ Department of Psychiatry, Shimoga Institute of Medical Sciences, Shimoga, India \\ ${ }^{2}$ Department of Pediatrics, Shimoga Institute of Medical Sciences, Shimoga, India \\ Email: *drramprasadks@gmail.com
}

How to cite this paper: Ramprasad, K.S. and Manjunathaswamy, R. (2018) Prevalence of Mental Retardation in Children of Shimoga District-An Overview. Open Journal of Psychiatry, 8, 115-119.

https://doi.org/10.4236/ojpsych.2018.82010

Received: December 13, 2017

Accepted: January 22, 2018

Published: April 11, 2018

Copyright $\odot 2018$ by authors and Scientific Research Publishing Inc. This work is licensed under the Creative Commons Attribution International License (CC BY 4.0).

http://creativecommons.org/licenses/by/4.0/

(c) (i) Open Access

\begin{abstract}
Background: Mental retardation is an important condition in children. People in the community need to be aware of the presence, need to act and prevent this problem. Mental retardation means mental growth of the child is not at par with physical growth. Mental retardation is calculated as intelligence quationent. $(\mathrm{IQ})=$ Mental age/chronological age $\times 100$. There are causes and can be categorized as prenatal, natal and postnatal factors. Mental retardation is classified as Mild Mental retardation IQ of 51 - 70; Moderate Mental retardation IQ of 36 - 50; Severe Mental retardation IQ of 21 - 35; Profound Mental retardation IQ of less than 20. IQ of $71-89$ is designated as borderline mental retardation. Objectives: Analyzing the procured data creates awareness in the society regarding mental retardation and its burden to the society. Results: The analysis is done using the data provided from the office of Deputy Director, Department of Public Instruction, Sarvashikshana Abhiyana (SSA) Shimoga District [1]. 555 children were having mental retardation ranging from mild to profound severity. The total number of children with various disabilities was 1185 , mental retardation alone was nearing $50 \%$ of the total disabilities. Conclusion: $50 \%$ of total disability was found to be mental retardation which needs to proliferate.
\end{abstract}

\section{Keywords}

SSA-Sarvashikshana Abhiyana, DDPI: Deputy Director of Public Instructions, Mental Retardation-MR

\section{Introduction}

Mental retardation is an important condition to be recognized and known to all members of the society. It states that the mental growth of the child is not at par as with norms for age, may be in motor, social, adaptive and speech areas. Men- 
tal retardation is defined as disparity in the growth of mind compared to the body growth for the said age and is been calculated [2] as IQ = Mental age/chronological age $\times 100$. The causes are many and can be categorized as prenatal, natal and postnatal factors. There are many causes; of them which can be controlled are maternal hypothyroidism, infections of both mother and child. Genetic or biological causes can be decreased by premarital counseling and avoiding consanguinity. In developing countries, poverty leading to malnourishment in the growing age of up to 5 years of age also plays an important key role. Mental retardation can be classified into mild, moderate, severe and profound based on severity. The Government of India has guidelines that those with this type of disabilities are given learning and financial aids for their support to lead their life independently. Intelligence quotient (IQ) measurement is the key to decide the severity of mental retardation. Mild Mental retardation IQ of 51 70; Moderate Mental retardation IQ of 36 - 50; Severe Mental retardation IQ of 21 - 35; Profound Mental retardation IQ of less than 20. IQ of 71 - 89 is designated as borderline Mental retardation [3]. The national centre for promotion of employment for disabled people (NCPEDP) argues that the disability is 5 - 6 percent of population; while the UNESCO (2007, p. 12) estimates the real prevalence could be around 40 million people in India [4].

Sarva Shiksha Abhiyana (SSA) is a Government of India that runs programme under the department of primary education. Focusing on Children with Special Needs (CWSN) for intervention is in major 8 areas:

1) Survey for identification of CWSN;

2) Assessment of CWSN;

3) Providing assistive devices;

4) Networking with NGO's/Government schemes;

5) Barrier free access;

6) Training of teachers in inclusive education;

7) Appointment of resource teachers;

8) Curricula Adaptation/Textbooks/Appropriate Teaching Learning Material.

The above steps have been adopted by the Government of India to uplift the children with multiple disabilities, with more stress on mental disabilities. However, the main limiting and highlighting factor is that once the mental retardation is set in, it has no treatment for its reversal. The effectiveness of other surviving and functioning neuronal cells in the brain can be enhanced by multiple modalities. The distribution of disabilities is also higher in the low socioeconomic groups and the need to focus on them is also a basic need for the community [5].

17 percent of the mental retarded children are been included in the main stream of education with other normal school going children [6]. SSA has included Home Based Education (HBE) for children with severe intellectual/physical disabilities, who can be educated in the combination of home based and alternate educational settings to enable them to achieve independent living skills [7]. Although, no evaluation/impact assessment studies are available to gauge the ef- 
ficacy of HBE programmes, research highlights the advantages in "Parents becoming effective teachers" and "Progress in overall development" in children [6]. Early childhood education in children below the age of 6 years is been done in Integrated Child Development Scheme (ICDS), where the focus is both on early education and supplementary nutrition [7].

Individualized education plans are also been included and teachers are been trained in this to help the children in framing themselves to the extent they can. Singal [8] and Jha [9] emphasizes the need for having a dedicated school, teachers and having a fore vision in developing a future society.

\section{Materials and Methods}

The analysis is done using the data provided from the office of Deputy Director, Department of Public Instruction, SSA, Shimoga District. This data includes enrolment of children of school going age in education department. Children who are taking home based rehabilitation services also, during the period of 2014-15. Mental Retardation was certified at District Hospital at Shimoga based on ICD: criteria. Ethical clearance is obtained.

\section{Results}

Table 1 and Figure 1 show the distributions of children with disabilities.

There were 555 children with mental retardation ranging from mild to profound severity. $62 \%$ of them were male children and $38 \%$ were female children.

Table 2 and Figure 2 show the total number of children with various disabilities.

Table 1. Sex distribution of mental retardation children.

\begin{tabular}{ccc}
\hline Male & Female & Total \\
\hline 342 & 213 & 555 \\
\hline
\end{tabular}

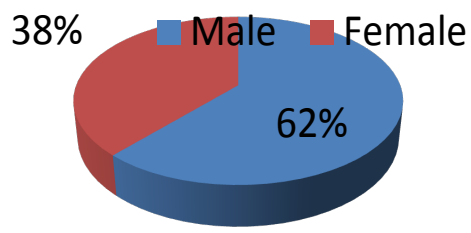

Figure 1. Sex distribution among the mentally retarded children.

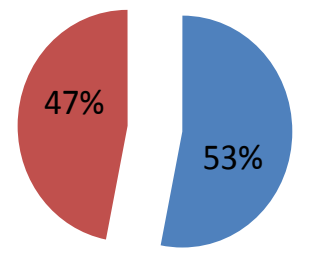

Others

Figure 2. Distribution of mental retardation among the total number of school children. 
Table 2. Distribution of mental retardation in school children.

\begin{tabular}{cc}
\hline Total number of school children & $\begin{array}{c}\text { Total number of school children } \\
\text { with Mental retardation }\end{array}$ \\
\hline 218072 & 555 \\
\hline
\end{tabular}

The total number of children with various disabilities was 1185, 555 (47\%) of total disability children were suffering from mental retardation. This accounts to almost $50 \%$ off the various disabilities in children. This accounts $0.25 \%$ school going children.

\section{Discussion}

Mental retardation is an entity which affects the growth of the brain. The key point is the ability to adjust, learn and inculcate new things needed in person's daily activity and modifying his or her way of understanding or thinking to effectively overcome the situation in a unique manner as compared to their peers, is affected. The number of children with mental retardation is as high as $50 \%$ off the total disability. This is due to the inclusion of pupils in and out of school. This is again dependent on the severity of mental retardation. Borderline mental retardation children are slow learners some children may have learning disability in specific subject also. Mild mental retardation children are able to grasp working skills than reading skills. Moderate mental retardation children can follow instructions of the caregivers for even simple day to day activities. Severe and profound mental retardation children need a complete assistance of the caregivers for all activities including personal hygiene care. This being the scenario, the attendance to the school by them is very less, with this background, SSA is providing the necessary facilities for home based education to improve the quality of life of such children and their caregivers through many locally available modalities. Male children were found to be outnumbered than female children. Many studies have been shown the need for special education, special teachers and special schools and are incorporated in SSA programme. The children are tried to bring them into the main stream of education, this is a strong boost to the child and the family of these children through SSA.

\section{Conclusion}

SSA provides the opportunity, the ability to inculcate and learn to meet the need of themselves to lead their life in the society. The non-rejuvenation property of the neurons adds to the pathology by inhibiting the repair process in mental retardation. This type of study needs replication in different districts for the formation of suitable policies for benefitting these children.

\section{References}

[1] Sarva Shiksha Abhiyan. Department of School Education and Literacy, MHRD, Government of India. 
[2] A Short Textbook of Psychiatry, Niraj Ahuja, $6^{\text {th }}$ Edition, Jaypee Publications, reprint 2008, Chapter on Mental Retardation, 169.

[3] Ministry of Social Justice and Empowerment, Government of India (2001) Guidelines for Evaluation of Various Disabilities and Procedures for Certification. New Delhi, Notification No. 16-18/97-NL.

[4] Paper Commissioned for the EFA Global Monitoring Report 2010, Reaching the Marginalized by UNESCO.

[5] SSA 2006:5. Discovering New Paths in Inclusion. A Documentation of Home Based Education Practices for CWSN in SSA. Department of EE \& L, Delhi. (MHRD)

[6] SSA 2006:6. Discovering New Paths in Inclusion. A Documentation of Home Based Education Practices for CWSN in SSA. Department of EE \& L, Delhi. (MHRD)

[7] Aggarwal, Y. (2008) Revitalization of Education Statistics in India. Issues and Strategies. http://www.dise.in./webpages/Edstat1.htm

[8] Singal, N. (2006) Inclusive Education in India: International Concept, National Interpretation. International Journal of Disability, Development and Education, 53, 351-369. https://doi.org/10.1080/10349120600847797

[9] Jha, M.M. (2002) Schools without Walls. Inclyusive Education for All. Heinemann, Oxford. 